\title{
The Old and the New in Prekallikrein Deficiency: Historical Context and a Family from Argentina with PK Deficiency due to a New Mutation (Arg541GIn) in Exon 14 Associated with a Common Polymorphysm (Asn124Ser) in Exon 5
}

Antonio Girolami, MD ${ }^{1}$ Josè Vidal, BSc ${ }^{2}$ Marcela Sabagh, BSc ${ }^{2}$ Nora Gervan, BSc ${ }^{2}$ Maria Parody, MD ${ }^{2}$ Edoardo Peroni, MSc ${ }^{1}$ Luisa Sambado, MSc $^{1}$ Hugo Guglielmone, MSc $^{2}$

\footnotetext{
${ }^{1}$ Department of Medicine, University of Padua Medical School, Padua, Italy 2 Department of Clinical Biochemistry and San Roque Hospital, Faculty of Chemical Sciences, National University of Cordoba, Cordoba, Argentina
}

Address for correspondence Antonio Girolami, MD, Department of Medicine, University of Padua Medical School, Via Ospedale Civile 105 Padua, Italy (e-mail: antonio.girolami@unipd.it).

Semin Thromb Hemost 2014;40:712.

ERRATUM

The author name, Marcela Sabagh, was misspelled in the author byline of the above article of Seminars in Thrombosis \& Hemostasis (volume 40, number 5, pp. 592-599) doi: 10.1055/ s-0034-1384767. The correct listing of the name Marcela Sabagh is mentioned above. The error was inadvertent and is regretted. 